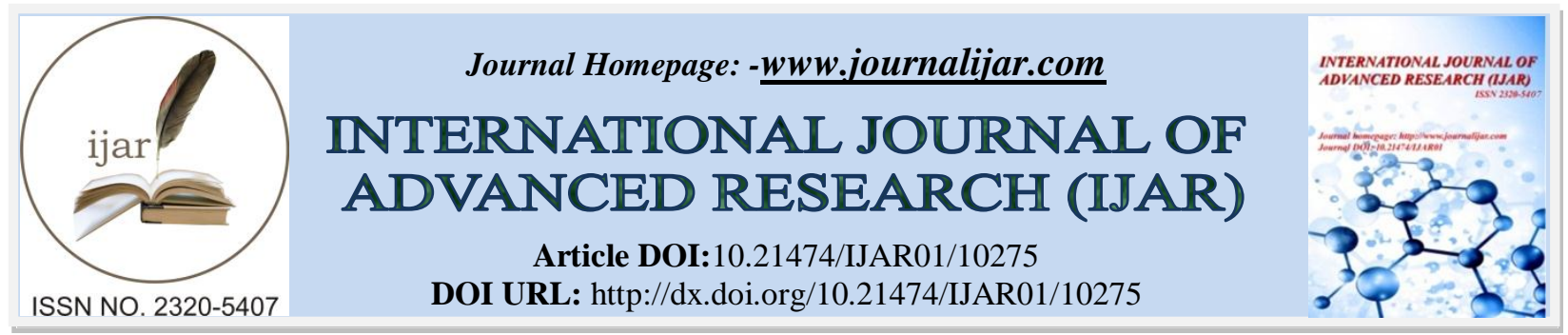

RESEARCH ARTICLE

\title{
PREVALENCE AND FACTORS ASSOCIATED WITH ROAD TRAFFIC CRASH AMONG BAJAJ AND MOTOR BICYCLE DRIVERS IN NEGELLE ARSI TOWN, OROMIA REGIONAL STATE, SOUTH EAST ETHIOPIA
}

\section{Ashebir Nigussie Yirgu ${ }^{1}$ and Segni Bekele Wakwaya ${ }^{2}$}

1. Department of Anesthesia, Negelle Arsi General Hospital and Medical College, Negelle Arsi, Ethiopia.

2. Department of Surgery, Negelle Arsi General Hospital and Medical College, Negelle Arsi, Ethiopia.

\section{Manuscript Info}

\section{Manuscript History}

Received: 23 November 2019

Final Accepted: 25 December 2019

Published: January 2020

Key words:-

Road Traffic Crash, Bajaj, Motor

Cycles, Prevalence, Negelle Town

\section{Abstract}

Background: A road traffic accident is a serious public health problem in the world. It is an accident that occurred on a way or street open to public traffic.

Objectives: To assess Prevalence and Factors Associated with Road Traffic Crash among Bajaj and Motor bicycle Drivers from March 2016 to April 2019 at Negelle Arsi Town, South-East Ethiopia.

Methods: Quantitative cross-sectional studies with a sample size of 330 drivers were conducted from April 10-20, 2019. The study was conducted among Bajaj and Motor bicycle drivers. After proportion to size allocation for Bajaj (206) and Motor bicycle (124) drivers, we used simple random sampling method. Data was collected with face to face interview using pretested questioners. Bivariate and multivariate analysis was done using SPSS version 21.

Results: Generally, among 322 total respondents, 92 (28.6\%) of the Bajaj and Motorcycle drivers ever had experience of road traffic accident in the last three years. Eight respondents were excluded from the study as a result of not availed during data collection and incomplete response to the survey. Out of the total drivers who were experienced road traffic accident, 70 (76.1\%) and 22(23.9\%) were Bajaj and Motorcycle drivers respectively. The mean age of the respondents was 26.5. All of them were 322 (100.0\%) males. Significant percent $261(81.0 \%)$ had a habit of using mobile phone while driving and 57(17.7\%) had experience of driving after drinking alcohol. More than half, $203(63.0 \%)$ followed the recommended speed limit of driving.271 (84.2\%) had not chewed chat and 120(37.3\%) were listened FM radio while driving. About 124(38.5\%) of them had experience of punishment or warning by traffic police.

Conclusions: 92 (28.6\%) of the Bajaj and Motorcycle drivers had experience of road traffic accident in the last three years. Risk factors identified includes vehicle Mechanical problems, Speedy driving, Listening Radio programme, Drink-driving, Chat-chewing and Mobile phone use while driving. Interventions targeted at developing negative attitude towards risky driving behaviors on drivers to bring positive behavioral changes. 
Copy Right, IJAR, 2020,. All rights reserved.

\section{Introduction:-}

As world health organization (WHO) defined, Road Traffic Accident (RTA) can be defined as "an accident that occurred on a way or street open to public traffic; resulted in one or more persons being killed or injured, and at least one moving vehicle was involved. Accordingly, Road traffic crash (RTC) is defined as a collision between two or more vehicles, between vehicles and pedestrians, between vehicles and animals, or between vehicles and fixed obstacles (Peden et al., 2004).

The report done by WHO in 2013 showed that more than 1.24 million people die every year as a result of road traffic injuries, making it "the eighth leading cause of death globally, and the leading cause of death for young people aged 15-29." Based on current trends, it is projected to be the fifth leading cause of death globally by 2030 (Violence, Prevention, Violence, Prevention, \& Organization, 2009).

Road traffic accidents (RTAs) have globally grown to become an epidemic. It's estimated to be responsible for up to $2 \%$ of global mortality and morbidity and becoming a major cause of death at a rate which is on a level with heart disease and cancer (Al Reesi et al., 2013).

In addition, when compared to the developed nations, causes for high burden in road traffic-related deaths and injuries in developing countries are primarily due to Growth in motor vehicle numbers, Poor enforcement of traffic safety regulations, Inadequacy of public health infrastructure, Poor access to health services, etc.(Nordberg, 2000).

The Ethiopian National Road Safety Coordination Office cites a road crash fatality rate of 114 deaths per 10000 vehicles per year but the actual figure may be higher due to improper reporting system (Al-Ghaweel, Mursi, Jack, \& Joel, 2009), (Gopalakrishnan, 2012). But, a mortality rate of one death per 10000 vehicles per year in the United Kingdom of Great Britain and Northern Ireland and an average mortality rate of 60 per 10000 vehicles across 39 sub-Saharan African countries (Al-Ghaweel et al., 2009).

Risk factors such as poor vehicle maintenance (including tires, brakes, and lights), choked roads, and driving old vehicles were identified in Ethiopia, India, and Libya [(Organization, 2010),(Chandran, Hyder, \& Peek-Asa, 2010), (Abegaz, Berhane, Worku, \& Assrat, 2014)].However, it should be noted that the causes of road crashes are normally multi-factors.

The aim of this study is to identify Prevalence and factors associated with road traffic crash among Bajaj and Motor bicycle drivers to provide a baseline data, to identify priorities and to develop targeted interventions and preventive measures to improve road safety among road users.

\section{Methods and Materials:-}

\section{Study design:}

Cross sectional study design was employed.

\section{Study area and period:}

The study was conducted at Negele Arsi town which is located in Oromia regional state in west Arsi Zone.It is one of the town of western Arsi zone of Oromia regional state which is located on the way to Shashemene approximately about $21 \mathrm{~km}$ away from Shashemene, capital town of West Arsi zone and 250km from Addis Ababa, a capital city of Ethiopia.

According to Negelle Arsi Woreda health office report, in 2019 G.C. the Woreda have total populations of 258,046 out of which $51 \%$ are Females and $49 \%$ are Males. And Woreda has 7 functional health centers.

According to Negele Arsi town health office report, in 2019 G.C. total populations of the town are 100,438 (50,020 Males and 50,418 Females). And the town has 3 health facilities [2 Hospitals (1 Private and 1 Government) and 1 Health Center].

According to town road and transport authority office report, there are around 500 Bajaj's under Tokkuma and Biftu associations and 300 motor bicycles are registered in 2019 and serving as method of transportations. 
The study was conducted from April 10-20, 2019.

Source population is all Bajaj and Motor bicycle drivers found and working in Negele Arsi Woreda, Negelle Arsi town from March 2016 to April 2019.

The study population included in the study was randomly selected Bajaj and Motor bicycle drivers found and working in Negele Arsi Woreda, Negelle Arsi town from March 2016 to April 2019.

Exclusion criteria -Those working at night time, come from nearby town and unavailable during study period.

\section{Sampling procedure and sample size determination:}

The sample size was calculated using the single population proportion formula, $\left.\mathrm{n}=\mathrm{Z}_{(1-\alpha / 2}\right)^{2} \mathrm{x} \mathrm{Pq} / \mathrm{d}^{2}$

Formula components are:-

1. $\mathrm{n}=$ number of sample size.

2. $Z=$ desired $95 \%$ confidence, $Z=1.96$.

3. $\mathrm{p}=$ percentage of Prevalence of RTA.

4. $q=1-p$; for this study, we presumed maximum variability, hence $\mathrm{p}=0.312$;

5. $\mathrm{q}=1-\mathrm{p}=1-0.312=0.688$

6. $\mathrm{d}=$ absolute allowable error, $5 \%$ of Sample size.

By expecting $31.2 \%$ of prevalence of RTA by Motor bicycles from assessed drivers at $95 \%$ confidence level, so $\mathrm{n}=(1.96)^{2} \times 0.312 \times(1-0.312) /(0.05)^{2}=330$.

Thus, the actual sample size for the study was $\underline{\mathbf{3 3 0}}$.

We obtained the list of the two kinds of vehicles in the area for sampling frame from April 10-20, 2019 at Negelle Arsi town. The study was done among a sample of 330 drivers of Bajaj (three tier vehicles) and Motorcycle drivers. After proportion to size allocation for Bajaj (206) and Motorcycle (124) drivers, we used simple random sampling method to identify illegible study subjects who meet the inclusion criteria.

\section{Data collection tools and procedure:}

Face to face interviews using pre-tested and structured questionnaires were used to collect data. Questionnaires were adapted from different literatures and modified to the current aim of the study which consisting of 43 questions used to measured road traffic accident as a collision between vehicles; between vehicles and pedestrians; between vehicles and animals; or between vehicles and fixed obstacle within three years period of time. The data collectors translate the English questionnaires for him/her self and interview the participants by their language. Motorcycle and Bajaj drivers identified with simple random sampling technique and the trained data collectors approached for the interview at their stations based on the information given from transport office of the town, taxi and Bajaj associations. Data was collected by one Nurse degree and one Anesthesia degree holders and supervised by principal investigator.

\section{Data Quality Assurance}

Data collectors were trained on each items included in the study tools, objective, right of respondents, confidentiality of information obtained and technique of interview. During data collection, regular supervision and follow up was made. Investigator was cross checked for completeness and consistency of data on daily basis. Once the data was collected and checked for completeness, consistency and accuracy, it was sorted, categorized and summarized. Then, we enter the data into the computer using developed data entry. Incomplete questionnaires were discarded and considered as none response rate.

\section{Data Analyzing and processing}

Data was checked manually for completeness and then coded and entered by investigators to SPSS version 20 computer program for cleaning and analysis. Descriptive statistics was used to determine the frequency of dependent and independent variables. Variables which show significant association on bivariate analyses were fitted in to multivariate logistic regression model to determine the independent predicators for RTC. Bivariate and multivariate 
analysis was used to identify associated factors of RTA and the strength of association was measured by $95 \%$ confidence interval and $\mathrm{P}$ - value of 0.05 was used as a cut of point.

\section{Ethical Consideration:}

Ethical clearance was obtained from Ethical Review Committee of NAGHMC and was produce for Negelle Arsi town Road and transport Authority Office and their official permission was taken. Informed Verbal consent was secured from every study participants before the start of interview. Confidentiality and anonymity were ensured.

\section{Result:-}

Socio-demographic and Drivers characteristics

A total of 322 participants completed the study questionnaires from the planned 330, giving a response rate of $97.6 \%$. Eight respondents were excluded from the study as a result of not availed during data collection or incomplete response to the survey. The mean age of the respondents was 26.5. All of the respondents $322(100.0 \%)$ were males. More than half $164(50.9 \%)$ were single in marital status, Muslim ( $\mathrm{n}=197,61.2 \%)$, Have no own Residency ( $n=204,63.4 \%)$, and Monthly income from2000.00-4000.00ETB ( $n=203,63.0 \%)$. Less than half of the respondents' educational status were secondary school $137(42.5 \%)$ followed by elementary school $126(39.1 \%)$. Almost half of the drivers were self-employed $(n=163,50.6 \%)$ meaning that they own their own taxi vehicles (Table 1).

\begin{tabular}{|c|c|c|c|}
\hline Variables & Category & Frequency & Percent (\%) \\
\hline \multirow{3}{*}{ Age } & $18-24$ & 174 & 54.0 \\
\hline & $25-31$ & 131 & 40.7 \\
\hline & $32-38$ & 17 & 5.3 \\
\hline \multirow[t]{3}{*}{ Marital Status } & Single & 164 & 50.9 \\
\hline & Married & 153 & 47.5 \\
\hline & Others(Divorced, widowed) & 5 & 1.6 \\
\hline \multirow{5}{*}{ Religion } & Orthodox & 81 & 25.2 \\
\hline & Muslim & 197 & 61.2 \\
\hline & Adventist & 9 & 2.8 \\
\hline & Protestant & 32 & 9.9 \\
\hline & Others & 3 & 0.9 \\
\hline \multirow{4}{*}{ Educational level } & Read and write & 8 & 2.5 \\
\hline & Elementary school & 126 & 39.1 \\
\hline & Secondary school & 137 & 42.5 \\
\hline & Diploma and above & 51 & 15.8 \\
\hline \multirow[t]{3}{*}{ Monthly income(ETB) } & Low $(<$ or $=2000.00 \mathrm{ETB})$ & 84 & 26.1 \\
\hline & Medium(>2000 to $<$ or $=4000 \mathrm{ETB})$ & 203 & 63.0 \\
\hline & $\operatorname{High}(>4000.00 \mathrm{ETB})$ & 35 & 10.9 \\
\hline \multirow[t]{2}{*}{ Owns their own residence } & Yes & 118 & 36.6 \\
\hline & No & 204 & 63.4 \\
\hline \multirow{3}{*}{$\begin{array}{l}\text { How many children you } \\
\text { have? }\end{array}$} & 0 children & 189 & 58.7 \\
\hline & $1-2$ children & 81 & 25.2 \\
\hline & Above 2 children & 52 & 16.1 \\
\hline \multirow[t]{2}{*}{ Owner of the taxi } & Self & 163 & 50.6 \\
\hline & Employer & 159 & 49.4 \\
\hline
\end{tabular}

Table1:- Socio-economic characteristics of Bajaj and Motocycles Drivers in Negelle Arsi town from March 2016 to April 2019, Negelle Arsi, Ethiopia.

Factors related to road traffic accident condition, Environmental, Seasonal and Geographical factors of the respondent:

Generally, among 322 total respondents, 92 (28.6\%) of the Bajaj and Motorcycle drivers ever had experience of road traffic accident in the last three years. Out of the total drivers who were experienced road traffic accident, 70 $(76.1 \%)$ and 22(23.9\%) were Bajaj and Motorcycle drivers respectively. 
Almost half of the respondents 159 (49.4\%) were driving their employers' vehicles. For majority of them, their driving experience was one year to two year, 238(73.9\%). Almost all 294(91.3\%) of them had not got first aid training. Majority 226(70.2\%) of them had no driving licence.

Within the period of the past 3 years, 124(38.5\%) of the respondents had experience of punishments or warnings by traffic police. Out of these $48(38.7 \%)$ of them had one to two, 61(49.2\%) had three to four and $15(12.1 \%)$ had more than four experience of punishment or warning by traffic police for violating traffic rules and regulations.

From the total respondents, $261(81.0 \%)$ of them were using mobile phone while driving vehicle. From these, $69(26.4 \%)$ of them reduce speed and receive calls, 183(70.1\%) of them stop driving and receive calls and only $9(3.4 \%)$ of them receive calls at normal range. $120(37.3 \%)$ of them were listened FM radio while driving.

More than half, 203 (63.0\%) of the respondents were following the recommended speed limit of driving in the town. From the total respondents, 119 (36.9\%) of them were drive over the limited speed. 88(73.9\%) of them occasionally drive more than the limited speed. The reasons given for why they do not follow the speed limit and drive more than the limited speed was because of to shorten the line77 (64.7\%) and to increase income $38(31.9 \%)$.

Only 57(17.7\%) of the respondents drink alcoholic beverage and from these 19(33.3\%), 13(22.8\%),23(40.3\%) and $2(3.5 \%)$ of them had an experience of driving within three hours of having alcoholic beverage occasionally, seldom ,never and very often respectively.

High proportions, $271(84.2 \%)$ of the respondents were not chewing chat while driving. Only 51(15.8\%) of them were used chewing chat. Out of these, $43(84.3 \%)$ of them used sometimes, $6(11.8 \%)$ of them used most of the time and only $2(3.9 \%)$ used always while driving. The explanations given by the participants were; they said that they were feel free in driving 29(56.9\%), it give them energy 16(31.4\%) and for pleasure while driving $6(11.8 \%)$.

In general, regarding Vehicles characteristics, 112 (34.8\%) of Bajaj and Motorcycle drivers stated as encounter mechanical problem within the last three years. Out of the total vehicles which encounter mechanical problem, 81 $(72.3 \%)$ and 31(27.7\%) were Bajaj and Motorcycle respectively. The common mechanical problems meets the vehicles were poor quality tires $(n=38,33.9 \%)$, broken breaks $(n=31,27.7 \%)$, lighting problem $(n=29,25.9 \%)$, steering system failure $(\mathrm{n}=13,11.6 \%)$ and 0thers $1(0.9 \%)$.Almost all, 309(95.9\%) of the vehicles had not got services for the last one year.

\section{Determinants or Multivariate analysis factors associated with RTC}

Among a total of 322 drivers, 92 self-reported involvement in a RTA in the past three years (2016-2019) for a prevalence of $28.6 \%$. Study participants reported $6(6.5 \%)$ passenger injury, 21(22.8\%) pedestrian and drivers injury equally, $47(51.1 \%)$ minor people injury, $9(9.8 \%)$ serious people injuries, and 36(39.1\%) property damage.

Twenty-one accidents (22.8\%) were happened in rainy weather condition while $73(79.3 \%)$ and 29(31.5\%)of the accidents happened in non-asphalt road and at commercial center respectively.

The most common cause of RTA were quality of road 28(30.4\%) followed by over speed driving $18(19.6 \%)$ and pedestrians carelessness $17(18.5 \%)$.

After applying both bivariate and multivariate logistic regression, four variables were found to be associated with road traffic accident. This includes, speedy driving, history of alcohol use, khat chewing and mechanical problems were found to increase the odds of Road traffic accident involvement. But, respond to mobile phone and Listening FM radio were not significantly associated with road traffic accident.

Road traffic accidents caused by vehicles with mechanical problems showed the strongest association (AOR = 10.086, 95\% CI: 5.609-18.136), followed by speedy driving (AOR = 2.635, 95\%CI: $1.554-4.469$ ), khat chewing $(\mathrm{AOR}=2.163,95 \% \mathrm{CI}: 1.091-4.289)$, and drink alcohol $(\mathrm{AOR}=1.947,95 \% \mathrm{CI}: 1.009-3.755)$.

RTA caused by speedy driving was 3 times more likely to cause RTA than those which do not use speedy driving $(\mathrm{AOR}=2.635,95 \% \mathrm{CI}: 1.554-4.469)$. 
Road traffic accident caused by mechanical problem of the vehicles was 10 times more likely to cause road traffic accident than those which do not caused by mechanical problems (AOR $=10.086,95 \%$ CI: 5.609-18.136).

Compared to drivers who were chewed chat and drink alcohol while driving, those who chew khat and drink alcohol were 2 times more likely to cause Road traffic accident (AOR $=2.163,95 \% \mathrm{CI}: 1.091-4.289$ ), and (AOR $=1.947$, 95\%CI: 1.009-3.755) respectively (Table-2).

\begin{tabular}{|c|c|c|c|c|c|}
\hline \multirow[t]{2}{*}{ S.no } & \multirow[t]{2}{*}{ Variables } & \multicolumn{4}{|c|}{$\begin{array}{l}\text { In the last } 3 \text { years, have you been involved in a road traffic } \\
\text { accident? }\end{array}$} \\
\hline & & $\mathrm{Yes}(\mathrm{N}=92)$ & $\mathrm{No}(\mathrm{N}=230)$ & P-value & \begin{tabular}{l|l} 
& AOR $(95 \% \mathrm{CI})$
\end{tabular} \\
\hline \multirow[t]{3}{*}{1.} & Drivers drink alcohol & & & & \\
\hline & Yes & $28(30.4 \%)$ & $29(12.6 \%)$ & 0.047 & $1.947(1.009-3.755)$ \\
\hline & No & $64(69.6 \%)$ & $201(87.4 \%)$ & $*$ & $*$ \\
\hline \multirow[t]{3}{*}{2.} & Drivers chew Khat & & & & \\
\hline & Yes & $27(29.3 \%)$ & $24(10.4 \%)$ & 0.027 & $2.163(1.091-4.289)$ \\
\hline & No & $65(70.6 \%)$ & $206(89.5 \%)$ & $*$ & $*$ \\
\hline \multirow[t]{3}{*}{3.} & $\begin{array}{l}\text { Drivers drive more than the limited } \\
\text { speed }\end{array}$ & & & & \\
\hline & Yes & $53(57.6 \%)$ & $66(28.7 \%)$ & 0.000 & $2.635(1.554-4.469)$ \\
\hline & No & $39(42.4 \%)$ & $164(71.3 \%)$ & $*$ & $*$ \\
\hline \multirow[t]{5}{*}{4.} & Method of receiving mobile calls & & & & \\
\hline & Reduces speed and receive & $24(26.1 \%)$ & $45(19.5 \%)$ & 0.613 & $1.242(0.536-2.878)$ \\
\hline & Stop driving and receive & $41(44.5 \%)$ & $142(61.7 \%)$ & 0.176 & $0.603(0.289-1.256)$ \\
\hline & Receiving at normal speed & $3(3.3 \%)$ & $6(2.6 \%)$ & 0.893 & $1.130(0.189-6.754)$ \\
\hline & Disconnect ringing & $24(26.1 \%)$ & $37(16.1 \%)$ & $*$ & $*$ \\
\hline \multirow[t]{3}{*}{5.} & Drivers listen Radio program & & & & \\
\hline & Yes & $45(48.9 \%)$ & $75(32.6 \%)$ & 0.083 & $1.596(0.941-2.705)$ \\
\hline & No & $47(51.1 \%)$ & $155(67.4 \%)$ & $*$ & $*$ \\
\hline \multirow[t]{3}{*}{6.} & Vehicle mechanical problem & & & & \\
\hline & Yes & $66(71.7 \%)$ & $46(20.0 \%)$ & 0.000 & $10.086(5.609-18.136)$ \\
\hline & No & $26(28.3 \%)$ & $184(80.0 \%)$ & $*$ & $*$ \\
\hline
\end{tabular}

Table 2:- Multivariate Analysis of associated factors related to RTC among Bajaj and Motor bicycles drivers in Negelle Arsi town from March 2016 to April 2019,Negelle, Ethiopia.

NB. * shows constant

\section{Discussions:-}

This study concentrated on 2 and 3 wheeled vehicle drivers, clarifying that about (28.6\%) of them had been involved in a Road traffic accident in the past three years. It is comparable to the prevalence described among different vehicles drivers in Vietnam (La, Lee, Meuleners, \& Van Duong, 2013).

In this study, even though use of mobile phone has insignificant association with RTA, 81\% ( $\mathrm{n}=261$ ) of the study participants were used mobile phone while driving. Similarly in other study, mobile phone use is constantly a risk factor for road traffic crash and $35 \%$ of the participants reported as using their mobile phones while driving (AlAseeri \& Oghuehi, 2013).

This study identified as $119,36.9 \%$ of the respondents were not following the limited speed of driving. It identified as speedy driving and Road traffic accident had a significant association. Comparable to our findings, speedy driving was associated with Road traffic accident in China(Zhang et al., 2013), Oman(Islam \& Al Hadhrami, 2012), and Nepal (Mishra, Sinha, Sukhla, \& Sinha, 2010). But, study in Australia speedy driving was not associated with road traffic accident(Lam, 2004). 
Previous studies in the USA have indicated that alcohol are highly related with road traffic accident (Harrison \& Fillmore, 2011), similar to this findings, our study detect as alcohol usage have significant association with RTA and result shows $57(17.7 \%)$ of the respondents were used alcoholic beverage. From these, 23(40.3\%) of them never drive within three hours of drinking alcohol.

Approximately $38.7 \%$ of drivers reporting road traffic accident association in our study had a history of at least one to two traffic punishments, and over 124 (38.5\%) of the total study participants had received a punishment. This shows as there is high level of risky driving behavior between the study populations(Asefa, Ingale, Shumey, \& Yang, 2016).

In contrast with previous studies in Ethiopia and other studies in low and middle income countries, our studies finding shown that Pedestrians accounted for higher percentage (22.8\%) of road traffic accident injury followed by vehicle drivers (21.7\%) [(Getachew et al., 2016), (Chalya et al., 2012)]. This might be due to inadequate footways and road signals in the town for pedestrian. Others may be public awareness on road traffic rules and behavior of drivers.

Different studies confirmed that young drivers are commonly involved in highest proportion of risk behaviors and traffic accidents than other age groups [(Beenstock \& Gafni, 2000), (Hassen, Godesso, Abebe, \& Girma, 2011)].Unlike to the above studies, in this particular study ( $\mathrm{n}=174,54.0 \%)$ of the drivers from 18-24 years old were involved to RTA than $(\mathrm{n}=131,40.7 \%)$ drivers from 25-31 years old.

Similar to previous study (Males, 2009), our study, even if educational status had no significant association with RTA, it shown that drivers with elementary and secondary school educational status $(\mathrm{n}=81,88 \%)$ had higher risky of road traffic accident than drivers with Diploma and above educational status ( $\mathrm{n}=10,10.9 \%)$. This may be because of drivers with lower educational status are not educated and less opportunities of occupation in other field.

In our study even though monthly income was a risk factor, it was not significantly associated with road traffic accident. Unlike this study, other research identified that high income was associated with high risky driving behavior [(Males, 2009), (Castle, Yi, Hingson, \& White, 2014)]. This might be defined as average monthly income increases, the ability to pay for vehicles and likely punishments increases.

Previous study showed as Alcohol consumption and abusing drugs with sedative properties lead drivers at a higher risk of road traffic accident by dropping their awareness and response time. In addition amphetamine can increases the self-confidence of the drivers and make them susceptible to more hazardous driving behaviors. Our study revealed that among drivers who consumed alcohol during work hours, $28(30.4 \%)$ of them result in RTA and $27(29.3 \%)$ of drivers who used chat chewing during driving was involved to road traffic accident in the last three years (de Carvalho Ponce, Muñoz, Andreuccetti, de Carvalho, \& Leyton, 2011).

\section{Limitations:}

1. Recall bias and survival bias may lead the prevalence to under-estimation.

2. Some of Bajaj and motorcycle drivers were not willing to participate.

3. Lack of comparable studies makes the comparison difficult because most of the literatures were hospital based.

\section{Conclusions:-}

Generally, among 322 total respondents, 92 (28.6\%) of the Bajaj and Motorcycle drivers ever had experience of road traffic accident in the last three years. Out of the total drivers who were experienced road traffic accident, 70 (76.1\%) and 22(23.9\%) were Bajaj and Motorcycle drivers respectively. The risk factors that were identified and associated with road traffic accident were Mechanical problems, Speedy driving, Drinking alcohol and Khatchewing.

\section{Recommendations:-}

Negelle Arsi town transport bureau should give training for drivers on rules related with speedy driving and avoiding of other risky driving behaviors. 
Health institutions should give health education to drivers and users of this transport services on preventive and educational actions regarding accidents and immediate measures.

Additional large prospective studies are needed to identify other factors associated with Road traffic accident.

\section{Funding:}

Nil

\section{Abbreviations:-}

1. RTA: Road Traffic Accident

2. RTC:-Road Traffic Crash

3. NAGHMC: Negelle Arsi General Hospital and Medical College

4. ETB: Ethiopian Birr

5. FCS: Fellowship of the College of Surgeons

6. ECSA: East Central and Southern Africa

\section{Competing interests:-}

We declared that we had no competing interests.

\section{Authors' contributions:}

AN has contributed to conducting case, drafted manuscript, review of literature, revision of manuscript; SB- have contributed to conducting case, drafted manuscript, review of literature, and revision of manuscript. All authors read and approve the final manuscript.

\section{Authors' Informations:-}

AN has Master in Advanced Clinical Anesthesia and now working in Negelle Arsi General Hospital and Medical College, department of Anesthesia as lecturer. SB has Specialty in General Surgery and FCS (ECSA), currently working in Negelle Arsi General Hospital and Medical College, department of Surgery as Assistant Professor.

\section{Acknowledgements:-}

We would like to thanks NAGHMC, all data collectors, and participants for their valuable informations. Also our deepest gratitude goes to Asst. prof. Mohammed Suleiman for his constructive advice and valuable comments.

\section{References:-}

1. Abegaz, T., Berhane, Y., Worku, A., \& Assrat, A. (2014). Effectiveness of an improved road safety policy in Ethiopia: an interrupted time series study. BMC public health, 14(1), 539.

2. Al-Aseeri, B., \& Oghuehi, K. C. (2013). Assessing the effects of mobile phone use, test messages and chatting on social media among Saudi and Non-Saudi drivers. International Journal of Applied, 3(7).

3. Al-Ghaweel, I., Mursi, S. A., Jack, J. P., \& Joel, I. (2009). Factors affecting road traffic accidents in Benghazi, Libya. Journal of family \& community medicine, 16(1), 7.

4. Al Reesi, H., Al Maniri, A., Plankermann, K., Al Hinai, M., Al Adawi, S., Davey, J., \& Freeman, J. (2013). Risky driving behavior among university students and staff in the Sultanate of Oman. Accident Analysis \& Prevention, 58, 1-9.

5. Asefa, N. G., Ingale, L., Shumey, A., \& Yang, H. (2016). 902 Prevalence and factors associated with road traffic crash among taxi drivers in mekelle town, Northern Ethiopia, 2014: a cross sectional study: BMJ Publishing Group Ltd.

6. Beenstock, M., \& Gafni, D. (2000). Globalization in road safety: explaining the downward trend in road accident rates in a single country (Israel). Accident Analysis \& Prevention, 32(1), 71-84.

7. Castle, I.-J. P., Yi, H.-Y., Hingson, R. W., \& White, A. M. (2014). State variation in underreporting of alcohol involvement on death certificates: Motor vehicle traffic crash fatalities as an example. Journal of studies on alcohol and drugs, 75(2), 299-311.

8. Chalya, P. L., Mabula, J. B., Dass, R. M., Mbelenge, N., Ngayomela, I. H., Chandika, A. B., \& Gilyoma, J. M. (2012). Injury characteristics and outcome of road traffic crash victims at Bugando Medical Centre in Northwestern Tanzania. Journal of trauma management \& outcomes, 6(1), 1. 
9. Chandran, A., Hyder, A. A., \& Peek-Asa, C. (2010). The global burden of unintentional injuries and an agenda for progress. Epidemiologic reviews, 32(1), 110-120.

10. de Carvalho Ponce, J., Muñoz, D. R., Andreuccetti, G., de Carvalho, D. G., \& Leyton, V. (2011). Alcoholrelated traffic accidents with fatal outcomes in the city of Sao Paulo. Accident Analysis \& Prevention, 43(3), $782-787$.

11. Getachew, S., Ali, E., Tayler-Smith, K., Hedt-Gauthier, B., Silkondez, W., Abebe, D., . . Edwards, J. (2016). The burden of road traffic injuries in an emergency department in Addis Ababa, Ethiopia. Public health action, 6(2), 66-71.

12. Gopalakrishnan, S. (2012). A public health perspective of road traffic accidents. Journal of family medicine and primary care, $1(2), 144$.

13. Harrison, E. L., \& Fillmore, M. T. (2011). Alcohol and distraction interact to impair driving performance. Drug and alcohol dependence, 117(1), 31-37.

14. Hassen, A., Godesso, A., Abebe, L., \& Girma, E. (2011). Risky driving behaviors for road traffic accident among drivers in Mekele city, Northern Ethiopia. BMC research notes, 4(1), 535.

15. Islam, M. M., \& Al Hadhrami, A. (2012). Increased motorization and road traffic accidents in Oman. Journal of Emerging Trends in Economics and Management Sciences, 3(6), 907-914.

16. La, Q. N., Lee, A. H., Meuleners, L. B., \& Van Duong, D. (2013). Prevalence and factors associated with road traffic crash among taxi drivers in Hanoi, Vietnam. Accident Analysis \& Prevention, 50, 451-455.

17. Lam, L. T. (2004). Environmental factors associated with crash-related mortality and injury among taxi drivers in New South Wales, Australia. Accident Analysis \& Prevention, 36(5), 905-908.

18. Males, M. (2009). Traffic Crash Victimizations of California Children and Teenagers by Drinking Over-21 Drivers. Californian Journal of Health Promotion, 7(2).

19. Mishra, B., Sinha, N. D., Sukhla, S., \& Sinha, A. (2010). Epidemiological study of road traffic accident cases from Western Nepal. Indian journal of community medicine: official publication of Indian Association of Preventive \& Social Medicine, 35(1), 115.

20. Nordberg, E. (2000). Injuries as a public health problem in sub-Saharan Africa: epidemiology and prospects for control. East African medical journal, 77(12 Suppl), S1-43.

21. Organization, W. H. (2010). Violence, injuries and disability: biennial report 2008-2009.

22. Peden, M., Scurfield, R., Sleet, D., Mohan, D., Hyder, A. A., Jarawan, E., \& Mathers, C. D. (2004). World report on road traffic injury prevention: World Health Organization Geneva.

23. Violence, W. H. O. D. o., Prevention, I., Violence, W. H. O., Prevention, I., \& Organization, W. H. (2009). Global status report on road safety: time for action: World Health Organization.

24. Zhang, X., Hongyan, Y., Guoqing, H., Mengjing, C., Yue, G., \& Xiang, H. (2013). Basic characteristics of road traffic deaths in China. Iranian journal of public health, 42(1), 7. 